\title{
RUPTURA DA BARREIRA HEMATOENCEFÁLICA APÓS INJEÇÃO DE DROGA GLIOTÓXICA NO TRONCO ENCEFÁLICO DE RATOS WISTAR
}

\author{
Eduardo Fernandes Bondan 1,2, Maria Anete Lallo, \\ Maria Lúcia Zaidan Dagli3, Luís Antonio Violin Dias Pereira ${ }^{4}$ \\ Dominguita Luhers Graça ${ }^{5}$
}

\begin{abstract}
RESUMO - O brometo de etídio (BE) determina desaparecimento astrocitário local, com ruptura da glia limitans e suposto dano na barreira hematoencefálica (BBB). Este estudo visou avaliar a integridade da BBB após injeção de solução de BE a 0,1\% (grupo E) ou de salina a 0,9\% (grupo C) na cisterna pontis de ratos Wistar. Fragmentos do tronco encefálico foram coletados das 24 horas aos 31 dias pós-injeção para estudo ultraestrutural e marcação imuno-histoquímica para a GFAP. Alguns animais receberam carvão coloidal por via intravenosa nos mesmos períodos. Nos ratos do grupo $C$, não houve sinal de perda astrocitária, nem extravasamento vascular de carvão no sítio da injeção. No grupo E, o desaparecimento astrocitário começou às 48 horas e algumas áreas estavam ainda destituídas de processos astrocíticos 31 dias após. Extravasamento de partículas de carvão nas lesões foi visto de 48 horas até 7 dias, não sendo detectada qualquer alteração ultra-estrutural das junções oclusivas pela falta de astrócitos perivasculares.
\end{abstract}

PALAVRAS-CHAVE: astrócitos, barreira hematoencefálica, sistema nervoso central, brometo de etídio, gliotóxico, ratos.

\begin{abstract}
Blood-brain barrier breakdown following gliotoxic drug injection in the brainstem of Wistar rats
ABSTRACT - Ethidium bromide (EB) causes local astrocytic disappearance, with glia limitans disruption and supposed blood-brain barrier (BBB) breakdown The aim of this study was to investigate the BBB integrity after the injection of $0.1 \%$ EB (group E) or $0.9 \%$ saline solution (group C) into cisterna pontis of Wistar rats. Brainstem fragments were collected from 24 hours to 31 days post-injection for ultrastructural study and GFAP immuno-histochemical staining. Some animals received colloidal carbon ink by intravenous route at the same periods. In rats from group C, there was no sign of astrocyte loss and no leakage of ink from blood vessels in the injection site. In group $\mathrm{E}$, astrocyte disappearance began at 48 hours and some areas were still devoid of astrocytic processes 31 days after. Leakage of carbon particles was seen from 48 hours to 7 days in the EB-induced lesions. Tight junctions did not show any detectable ultrastructural change due to the lack of perivascular astrocytes.
\end{abstract}

KEY WORDS: astrocytes, blood-brain-barrier, central nervous system, ethidium bromide, gliotoxic, rats.

O agente gliotóxico brometo de etídio (BE - 3,8diamino-5-etil-6-fenil-fenantridina) determina no sistema nervoso central (SNC) desaparecimento astrocitário local e lesões de desmielinização primária1-12, com invasão de células de Schwann, de células piais e de linfócitos para o neurópilo 6 . Poucos estudos têm focalizado as alterações induzidas na barreira hematoencefálica (BBB) sob tais condições, permanecendo incerto o caráter de reversibilidade ou não destas alterações. A BBB é relativamente impermeável a íons, vários aminoácidos, pequenos peptídios e principalmente proteínas, tendo como principal função regular o transporte de substâncias entre o sangue e o tecido nervoso, de forma a manter, assim, o ambiente neural protegido de substâncias neurotóxicas e de variações bruscas na composição sanguínea ${ }^{13,14}$. A barreira atua ainda excluindo células inflamatórias do SNC normal ${ }^{14,15}$. A presença as-

\footnotetext{
${ }^{1}$ Universidade Paulista (UNIP), São Paulo SP, Brasil; ${ }^{2}$ Universidade Bandeirante, São Paulo SP, Brasil; ${ }^{3}$ Departamento de Patologia, Faculdade de Medicina Veterinária, Universidade de São Paulo (USP), São Paulo SP, Brasil; ${ }^{4}$ Departamento de Histologia e Embriologia, Universidade Estadual de Campinas (UNICAMP) Campinas SP, Brasil; ${ }^{5}$ Departamento de Patologia, Universidade Federal de Santa Maria (UFSM), Santa Maria RS, Brasil.
}

Recebido 12 Novembro 2001, recebido na forma final 31 Janeiro 2002. Aceito 14 Fevereiro 2002.

Dr. Eduardo Fernandes Bondan - Rua Batataes 523/152 - 01423-010 São Paulo SP - Brasil. E-mail: bondan@uol.com.br 
trocitária se faz necessária para a indução e manutenção da $\mathrm{BBB}^{16,17}$, a qual, nos vertebrados, se localiza entre as células endoteliais dos capilares do SNC, que são contínuos e diferem morfológica e funcionalmente dos demais capilares do organismo ${ }^{18,19}$. A principal condição da existência desta barreira é a presença junções oclusivas de alta resistência, tipo zonula occludens, entre as células endoteliais, impedindo dessa forma o fluxo intercelular ${ }^{16,17,20}$. Além disso, poucas vesículas pinocíticas são encontradas no endotélio do SNC, limitando o fluxo transcelular ${ }^{21}$.

A possibilidade de reestruturação da BBB após desmielinização com destruição astrocitária tem sido pouco estudada. Áreas remielinizadas por células de Schwann na medula espinhal de ratos parecem possuir barreira íntegra ${ }^{22}$, enquanto placas crônicas inativas da esclerose múltipla apresentam defeito contínuo para proteínas ${ }^{23}$.

Nesse contexto, a presente investigação visou avaliar os efeitos da injeção intracisternal de BE, no tronco encefálico de ratos Wistar, sobre a integridade da BBB no sítio de lesão, tentando estabelecer o padrão de competência da mesma nas lesões em diferentes períodos de observação. Avaliação morfológica da barreira foi realizada através da observação da presença astrocitária ao redor dos vasos sanguíneos das áreas de lesão, mediante marcação imuno-histoquímica dos astrócitos para a proteína glial fibrilar ácida (GFAP), assim como por observação ultraestrutural destes vasos. Em tais áreas, foi observada a presença ou não de prolongamentos astrocitários ao redor dos vasos sanguíneos, a complexidade e extensão das junções oclusivas entre células endoteliais vizinhas e a presença ou não de elementos infiltrativos no SNC, tais como células meníngeas, células de Schwann e linfócitos. Já a avaliação funcional foi feita observando-se o grau de marcação dos vasos com carvão coloidal em diferentes períodos pós-injeção do BE. Os resultados obtidos foram comparados com aqueles de animais normais e de animais injetados intracisternalmente com o mesmo volume de solução salina a 0,9\%, a fim de permitir a análise do grau de participação individual do gliotóxico e do trauma da injeção sobre a integridade da barreira.

\section{MÉTODO}

Foram utilizados 86 ratos Wistar, machos, de 4 a 6 meses de idade, divididos em 3 grupos: $\mathrm{H}(\mathrm{n}=6)$, compreendendo animais tomados como controles histológicos normais; $E(n=48)$, de animais injetados na cisterna pontis com solução de BE a $0,1 \%$; $C(n=32)$, de animais injetados com solução salina a $0,9 \%$.
Os animais foram anestesiados com quetamina e xilazina $(5: 1 ; 0,1 \mathrm{ml} / 100 \mathrm{~g})$ e, com auxílio de um motor de teto, de uso odontológico, e de broca de número 2 , foi feito orifício na calota óssea a $0,85 \mathrm{~cm}$ póstero-diagonalmente e à direita do bregma até a exposição da duramáter. Com o uso de seringa de Hamilton, de agulha removível de calibre 26s, foram injetados na cisterna pontis (basal), um alargamento do espaço subaracnoideo na superfície ventral da ponte, $10 \mu \mathrm{l}$ de solução de BE a 0,1\% nos animais do grupo $E$ e o mesmo volume de solução salina a $0,9 \%$ em animais do grupo $C$. Os ratos foram anestesiados e submetidos à perfusão intracardíaca com solução de formol tamponado a 10\% (para o estudo imuno-histoquímico) ou solução de glutaraldeído a $4 \%$ em tampão fosfato de Sorensen ( $\mathrm{pH} 7,2-7,4$ - para o estudo ultra-estrutural) às 24 e 48 horas e aos 3, 7, 11, 15, 21 e 31 dias pós-injeção. Cortes do tronco encefálico (ponte, mesencéfalo e bulbo) foram imersos em solução de formol tamponado a $10 \%$ por 72 horas para posterior desidratação, diafanização e inclusão em parafina. Cortes transversais de $5 \mu \mathrm{m}$ foram corados pela técnica de hematoxilinaeosina (H-E) e cortes de blocos selecionados foram colhidos em lâminas tratadas com silano a $4 \%$, desparafinadas em xilol e hidratadas em série decrescente de etanóis. 0 método utilizado para a marcação imuno-histoquímica da GFAP foi o da avidina-biotina segundo Hsu e colaboradores $^{24}$. Os cortes foram incubados durante 16 horas a $4^{\circ} \mathrm{C}$, com o anticorpo policlonal primário anti-GFAP (Rabbit AntiCow GFA, Code Number ZO334, Dako) na diluição 1:1000. A seguir, foram incubados por 30 minutos com o anticorpo secundário biotinilado anti-imunoglobulina de coelho (Duet Kit DAKO) na diluição 1:400 e após com o conjugado estreptavidina-biotina-peroxidase (Duet Kit DAKO) por mais 30 minutos. Imunorreatividade foi visualizada usando diaminobenzidina (DAB, Sigma) a 0,1\% como cromógeno e $\mathrm{H}_{2} \mathrm{O}_{2}$ a $0,5 \%$.

Para o estudo ultra-estrutural, foram colhidos fragmentos da porção ventral da ponte, mesencéfalo e bulbo, posteriormente pós-fixados em tetróxido de ósmio $\left(\mathrm{OsO}_{4}\right)$ a $1 \%$, desidratados em série crescente de acetonas e embebidos em resina Araldite 502, após estágios transicionais em acetona. Cortes semifinos $(0,5-1,0 \mu \mathrm{m})$ foram obtidos e corados com solução de azul de toluidina a $0,25 \%$ em borato de sódio a $1 \%$. Cortes ultrafinos (60-90 nm de espessura), obtidos a partir de áreas selecionadas, foram contratados com solução de acetato de uranila a $2 \%$ e citrato de chumbo, sendo examinados em microscópio eletrônico de transmissão Phillips EM-201.

Animais de diferentes grupos e períodos foram injetados por via endovenosa com carvão coloidal $(0,1 \mathrm{ml} / 100 \mathrm{~g})$ para marcação vascular segundo Majno e Palade ${ }^{25}$. Vinte minutos após, foram perfundidos por via intracardíaca com solução de formol tamponado a 10\%. Amostras de tronco encefálico foram submetidas à desidratação, diafanização e inclusão em parafina, obtendo-se cortes seriados de aproximadamente $5 \mu \mathrm{m}$ corados pelo método da H-E. 

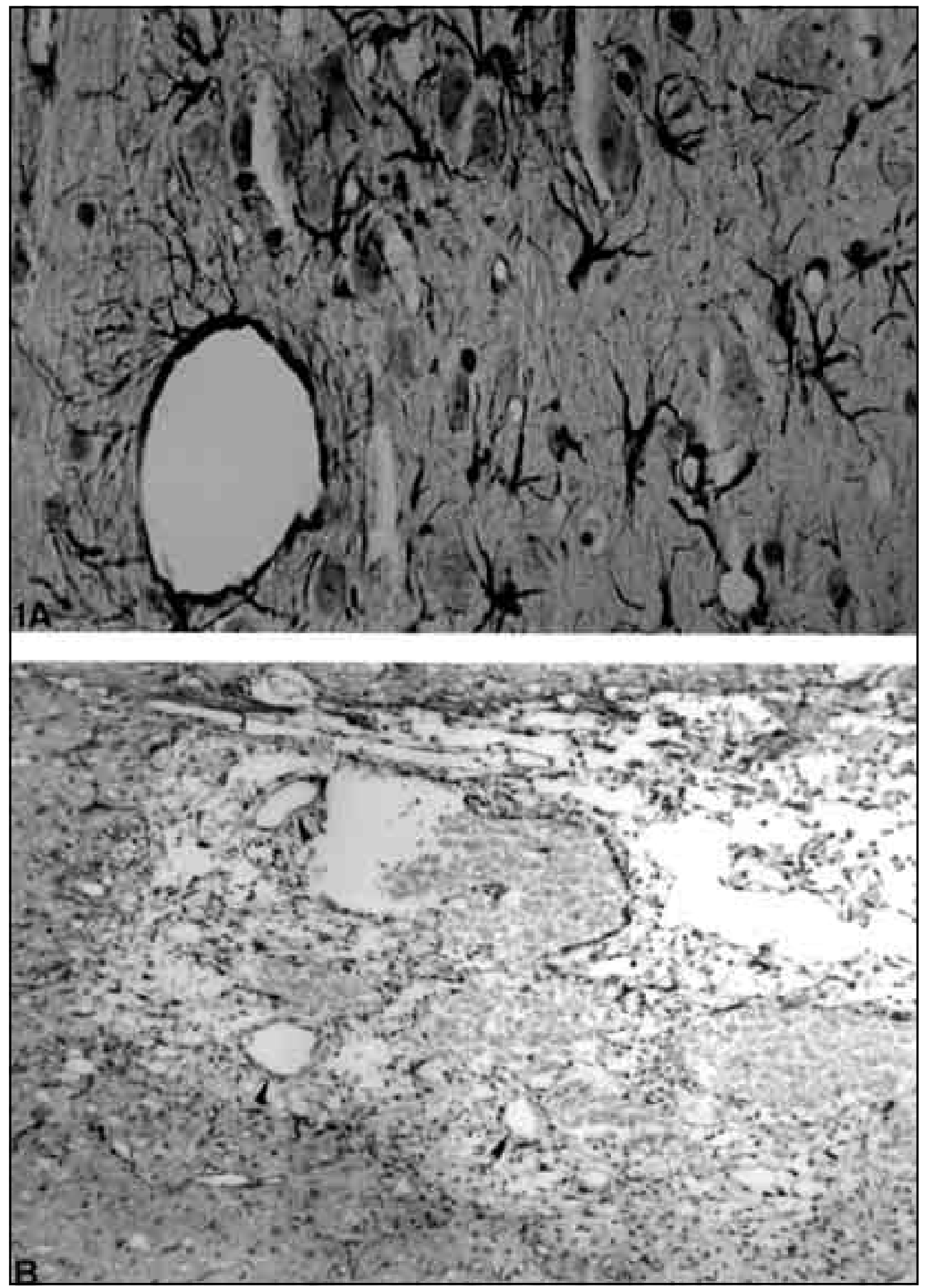

Fig 1A. Aspecto normal da ponte de rato Wistar com marcação imuno-histoquímica para GFAP. Astrócitos e seus processos são visualizados ao redor de vasos sanguíneos e de corpos celulares neuronais. Grupo H. GFAP - Obj. 40x. Fig 1B. Lesão 3 dias após a injeção do BE. Notar a ausência de células GFAP-positivas no centro da mesma, inclusive ao redor de vasos sanguíneos (cabeça de seta). Grupo E. GFAP - Obj. 10x. 


\section{RESULTADOS}

As lesões induzidas pela injeção de BE concordam com aquelas descritas anteriormente no tronco encefálico de ratos ${ }^{1-6,10-12,26}$, sendo aqui só descritas as observações pertinentes à presença astrocitária perivascular e as características ultra-estruturais das junções oclusivas interendoteliais e dos vasos sanguíneos do SNC.

Nos cortes marcados para a GFAP, os astrócitos foram identificados pela coloração marrom de seu citoplasma em contraste com o roxo azulado do seu núcleo, tendo sido invariavelmente encontrados ao redor dos vasos sanguíneos locais no tronco encefálico dos animais pertencentes aos grupos $\mathrm{H}$ (Fig 1A) e C.

Nas áreas centrais das lesões induzidas pelo BE (grupo E), observou-se o claro desaparecimento astrocitário (inclusive perivascular) das 48 horas aos 31 dias pósinjeção do gliotóxico (Fig 1B), enquanto que, nas regiões mais periféricas, alguns vasos sanguíneos já mostravam a partir do $15^{\circ}$ dia processos astrocitários circundantes fortemente imunorreativos para a GFAP.

A análise ultra-estrutural da ponte dos animais controles permitiu caracterizar os astrócitos como células de núcleo pálido oval, esférico ou irregular, com uma fina camada de cromatina delimitando o envoltório nuclear, além de um nucléolo às vezes não proeminente e processos citoplasmáticos exten- sos contendo feixes de fibrilas gliais. Prolongamentos astrocitários eram claramente observados ao redor dos vasos sanguíneos da região.

Os capilares do tronco encefálico foram visualizados com paredes delgadas, porém espessando-se na região do núcleo achatado da célula endotelial. O núcleo apresentava cromatina relativamente homogênea, mas condensada logo abaixo do envoltório nuclear. Vesículas pinocíticas eram pouco observadas.

$\mathrm{Na}$ junção interendotelial, as duas membranas citoplasmáticas apostas permaneciam paralelas, separadas por espaço de cerca de $15 \mathrm{~nm}$. Ao longo da interface e próximo à terminação luminal de cada junção, as duas membranas normalmente se fundiam para formar zônulas de oclusão, com obliteração do espaço intercelular.

Externamente às células endoteliais, era observada uma lâmina basal fina e contínua, às vezes separada da lâmina basal verdadeira do parênquima por espaço perivascular estreito, onde os prolongamentos astrocitários terminais repousavam. Às vezes, as lâminas basais endotelial e do parênquima se uniam, formando uma lâmina contínua, com desaparecimento do espaço perivascular.

Pericitos, quando observados, estavam presentes no espaço perivascular, completamente envolvidos por membrana basal. Apresentavam núcleo

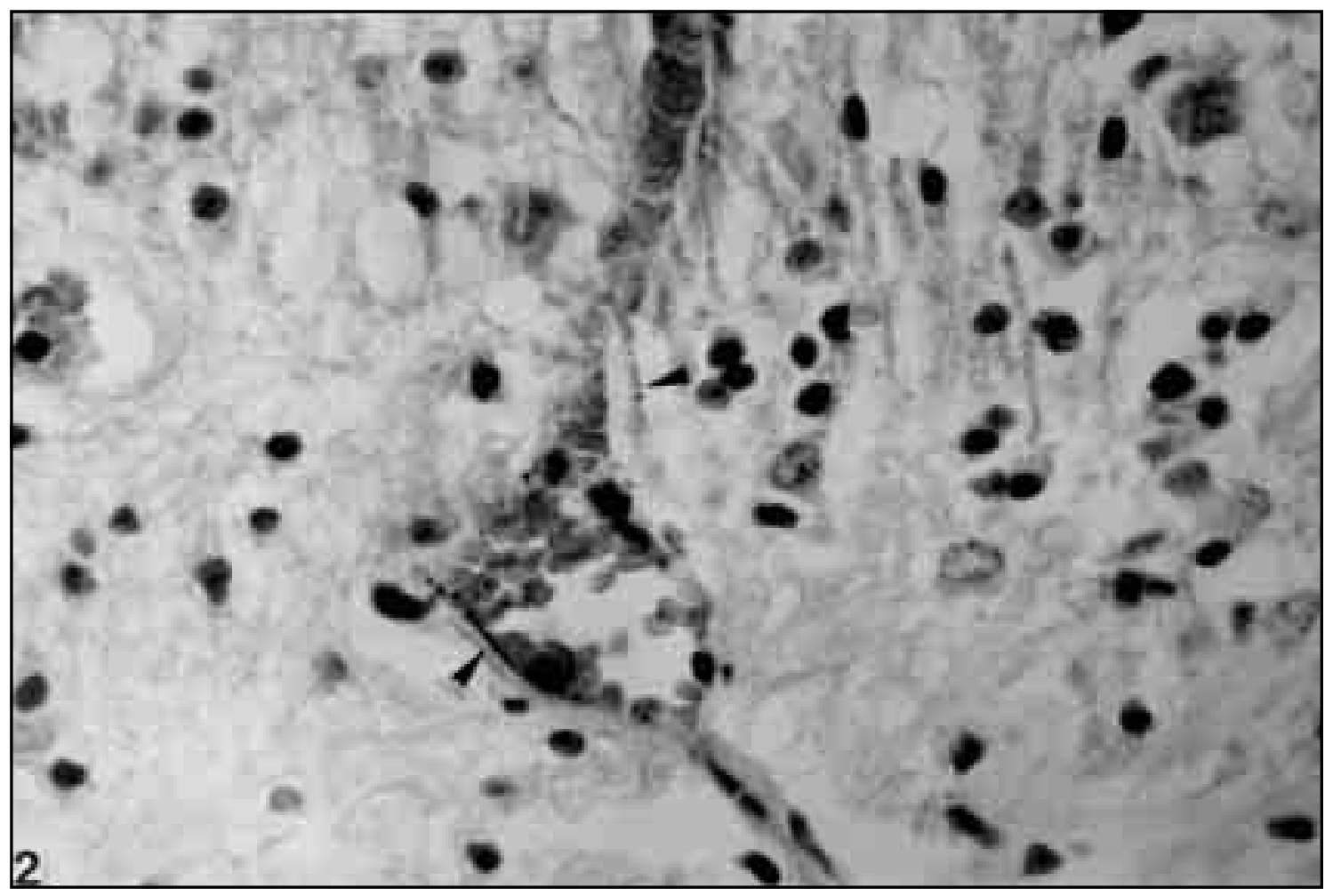

Fig 2. Partículas de carvão coloidal (cabeça de seta) depositadas junto à parede de vaso sanguíneo em área central de lesão induzida pelo BE. Grupo E. Lesão de 7 dias. Grupo E. HE - Obj. 40x. 

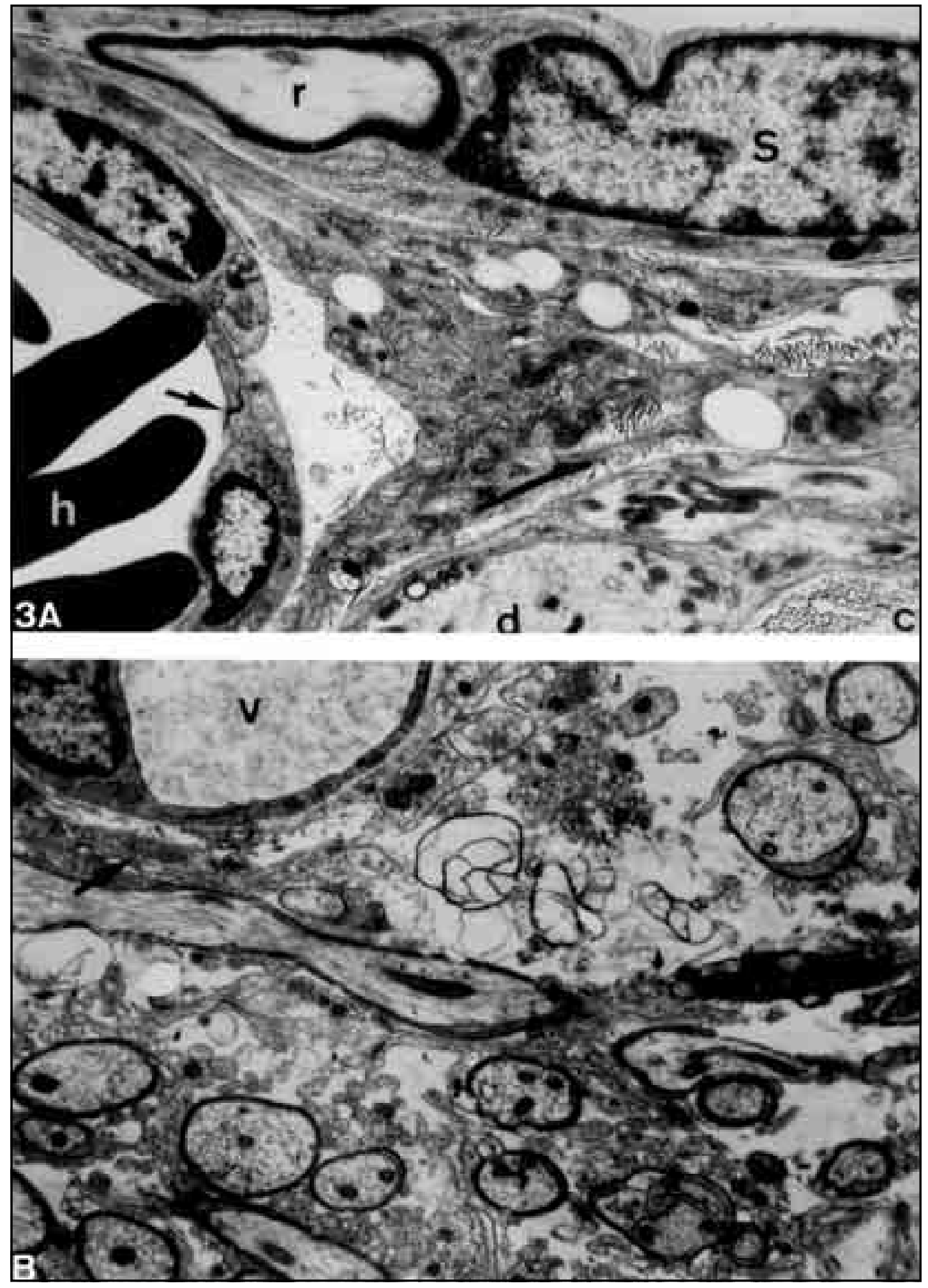

Fig 3A. Vaso sanguíneo exibindo junção oclusiva (seta) em área contendo células de Schwann (S) em estágios iniciais de associação com axônios desmielinizados (d) ou já em processo de remielinização (r). Notar a presença de hemácias (h) na luz vascular e a grande quantidade de fibras colágenas (c) no espaço extracelular. Grupo E. Lesão de 21 dias. Micrografia eletrônica - 13.388x. Fig 3B. Vaso sanguíneo (v) em área de remielinização oligodendroglial e processos astrocitários associados (seta). Grupo E. Lesão de 31 dias. Micrografia eletrônica - 13188x. 
fusiforme ou alongado, cromatina condensada logo abaixo do envoltório nuclear, citoplasma denso como o da célula endotelial e, ao contrário desta, pericitos frequentemente continham corpos densos que lembravam lisossomos.

Os animais dos grupos H e C não apresentaram qualquer extravasamento vascular das partículas de carvão, enquanto aqueles provenientes do grupo $\mathrm{E}$ exibiram vazamento observável das 48 horas aos 7 dias pós-injeção (Fig 2), presente sobretudo nas áreas centrais das lesões que se estendiam do mesencéfalo à ponte. A saída de partículas coloidais nos capilares analisados e sua deposição junto à parede vascular ocorreu simultaneamente à presença de junções oclusivas aparentemente normais, conforme observado por análise das micrografias eletrônicas dos animais do grupo E. Tal extravasamento não foi encontrado nos animais do grupo $\mathrm{C}$ e não houve, em nenhum período avaliado, desaparecimento dos processos astrocitários circundantes neste grupo, nem observação de células piais, de Schwann ou linfócitos infiltrantes.

Já nos animais do grupo $E$, foram encontrados, sobretudo nas áreas centrais da lesão, vasos sanguíneos destituídos de prolongamentos astrocitários associados até os 31 dias pós-injeção do gliotóxico. Às 24 horas, já era possível observar mudanças associadas aos vasos e restritas inicialmente aos pericitos, os quais mostravam citoplasma eletroluscente e condensação da cromatina nuclear, embora as células endoteliais ainda se apresentassem de aparência normal. Três dias após a injeção do BE, algumas poucas células endoteliais no centro da lesão apresentavam-se edemaciadas, enquanto aquelas de vasos periféricos tinham aspecto normal. Aos 7 dias, as células endoteliais do centro da lesão mostravam-se espessadas e continham maior densidade de mitocôndrias e filamentos em relação ao normal. O núcleo apresentava um contorno dobrado, contendo proeminente nucléolo. Estavam circundadas por lâmina basal, mas sem apresentar pericitos e prolongamentos astrocíticos associados. Ocasionalmente, era encontrada em tais áreas evidência de proliferação endotelial, embora somente aos 11 dias a hipertrofia e a hiperplasia vascular se constituíram em achados importantes. Os vasos periféricos ao centro da lesão já exibiam processos astrocitários associados, muitas vezes incipientes e finos, outras vezes hipertróficos e contendo abundantes feixes de filamentos gliais, além de estarem envoltos por proeminente membrana basal.

Dos 15 aos 31 dias pós-injeção, os achados endoteliais repetiam aqueles descritos acima; no entanto, pequenas projeções citoplasmáticas esten- didas para o lúmen vascular se mostravam mais frequentes. Foi observado que células endoteliais localizadas em áreas contendo células de Schwann remielinizantes continham pequeno número vesículas pinocíticas, de forma similar às áreas contendo processos astrocitários. Além disso, a partir dos 15 dias era comum o achado de células piais infiltrantes formando cordões ou ninhos monotípicos ao redor dos vasos sanguíneos em áreas periféricas à lesão induzida pelo gliotóxico.

Remielinização por células de Schwann foi encontrada a partir dos 15 dias pós-injeção do BE em áreas destituídas de processos astrocitários (Fig 3A), enquanto a reconstrução mielínica de origem oligodendroglial coincidia com o reaparecimento dos mesmos (Fig 3B).

Quanto ao extravasamento vascular, a partir dos 11 dias pós-injeção de $\mathrm{BE}$, os vasos sanguíneos do centro e da periferia das lesões induzidas não mais exibiam marcação detectável de partículas de carvão entre o endotélio e a membrana basal.

\section{DISCUSSÃO}

As lesões induzidas pela injeção de BE concordam com aquelas descritas em estudos anteriores no tronco encefálico de ratos ${ }^{2-4,6}$. Perda astrocitária foi detectada a partir das 48-72 horas pós-injeção e algumas áreas centrais da lesão permaneceram destituídas de processos astrocíticos até 31 dias depois.

Experimentos in vivo mostraram que o BE permanece por até 72 horas no tecido da medula espinhal, provocando fluorescência característica em células no centro da lesão, na superfície subpial e ao longo dos vasos sanguíneos, áreas cujas células gliais, notadamente astrócitos, desapareceram ou mostraram sinais de intoxicação severa ${ }^{9}$. Uma vez que os astrócitos são os grandes responsáveis pela indução e manutenção da BBB ao determinarem a formação de junções oclusivas entre células endoteliais vizinhas ${ }^{17}$, acredita-se que, pelo menos transitoriamente, as áreas de lesão apresentem quebra da mesma, com maior permeabilidade vascular e entrada de células inflamatórias no $\mathrm{SNC}^{14}$.

No presente estudo, extravasamento de partículas de carvão foi visto de 48 horas até 7 dias nas lesões do BE e pareciam estar confinadas entre o endotélio e a membrana basal dos vasos sanguíneos locais. Não foi detectada, no entanto, qualquer alteração ultraestrutural significativa nas junções oclusivas entre células endoteliais vizinhas em vasos sanguíneos destituídos de processos astrocitários circundantes. Por outro lado, os ratos injetados com solução salina não 
exibiram perda astrocitária e nenhum extravasamento de carvão coloidal foi identificado a partir dos vasos sanguíneos no sítio da injeção.

Em tentativa de modulação farmacológica do processo remielinizante no modelo gliotóxico do $\mathrm{BE}$, observou-se que o uso do imunossupressor ciclosporina, o qual não atravessa normalmente a BBB íntegra, foi capaz de modificar o processo de reparo das lesões, as quais exibiam maior densidade de oligodendrócitos remielinizantes por provável efeito proliferativo induzido pelo agente imunomodulador sobre as células progenitoras oligodendrogliais ${ }^{2,3}$. A ausência astrocitária, associada à presença invasiva de células de Schwann, de linfócitos e de células piais nas áreas de lesão ${ }^{6}$, bem como a observação de interferência no processo remielinizante com uma droga que não tem acesso normal ao tecido nervoso ${ }^{23}$, são fortes indícios de que existe perturbação da BBB pela ação gliotóxica do BE sobre os astrócitos ou talvez pelo próprio trauma da injeção.

Injeções de $\mathrm{BE}$ na medula espinhal ${ }^{7-9}$ e no tronco encefálico ${ }^{1-6,10-12,26}$ de ratos induzem mudanças degenerativas na oligodendróglia, com subsequente desmielinização dos axônios cujas bainhas de mielina são por eles mantidas. Abundante infiltrado macrofágico, restos mielínicos e axônios nus constituem os principais achados da área central das lesões induzidas pelo BE. No tronco encefálico, remielinização só se torna aparente a partir do $12^{\circ} \mathrm{dia}$, com observação dos oligodendrócitos sobreviventes associados a axônios envoltos por finas bainhas de mielina, assim como eventuais células de Schwann, localizadas em áreas subpiais e perivasculares e exibindo grau mais avançado de reparo mielínico, embora quantitativamente menos importante que o realizado pelos oligodendrócitos ${ }^{11,12}$. A presença invasiva de células de Schwann no SNC costuma ser atribuída ao desaparecimento local dos astrócitos, permitindo livre acesso das mesmas a partir das fibras nervosas da pia-máter, das fibras associadas aos vasos de maior calibre do SNC ou ainda daquelas oriundas de nervos cranianos originários da ponte ${ }^{10}$.

Uma vez que o extravasamento de partículas de carvão não foi encontrado nos animais do grupo $C$, sugere-se que o trauma da injeção não foi por si só capaz de alterar a função restritiva das junções interendoteliais.

Um aspecto importante a ser ressaltado foi a presença de vasos sanguíneos destituídos de processos astrocitários circundantes até os 31 dias pós-injeção do $B E$, o que poderia sugerir inicialmente a inexistên- cia de uma BBB plenamente desenvolvida, dada a necessidade de proximidade entre os pés astrocitários e as células endoteliais neurais para a expressão de junções oclusivas entre elas ${ }^{16,17}$. No entanto, junções oclusivas foram invariavelmente visualizadas neste estudo em todos os períodos avaliados, mesmo nas áreas centrais das lesões. Dessa forma, é provável que a observação morfológica dessas junções não seja suficientemente conclusiva para avaliar aspectos funcionais relativos à permeabilidade dos vasos encefálicos.

Tal argumento é fortalecido pelo achado de extravasamento de carvão coloidal às 48 e 72 horas e aos 7 dias após injeção do $\mathrm{BE}$, quando junções oclusivas aparentemente desenvolvidas podiam ser encontradas entre células endoteliais adjacentes.

Quanto à inexistência ocasional de processos astrocitários associados aos vasos sanguíneos observados, é importante ressaltar que Felts e colaboradores ${ }^{22}$ encontraram, após destruição oligodendroglial e astrocitária induzida por BE na medula espinhal de ratos, BBB competente em áreas de remielinização completa por células de Schwann, o que foi demonstrado pela relativa ausência de extravasamento de peroxidase (horseradish peroxidase), mesmo em ausência de células GFAP-positivas.

\section{REFERÊNCIAS}

1. Bondan EF, Lallo MA, Graça DL. Desmielinização experimental por brometo de etídio no sistema nervoso central. Rev Univ Guarulhos Ciênc Biol Saúde 1998;5:19-32.

2. Bondan EF, Lallo MA, Graça DL. Efeitos do brometo de etídio no tronco encefálico de ratos Wistar imunossuprimidos com ciclosporina. São Paulo: Coleção Cadernos de Estudos e Pesquisas UNIP, 1998:1-46.

3. Bondan EF, Graça DL, Sinhorini IL, Lallo MA, Silva IM. Pharmacological interference on remyelination in rats submitted to the ethidium bromide model. Arch Anat Cytol Path/Clin Exp Path 1998;46:536.

4. Bondan EF, Lallo MA, Sinhorini IL, Graça DL. Schwann cells may express an oligodendrocyte-like remyelinating pattern following ethidium bromide injection in the rat brainstem. Acta Microscopica 1999;8:707-708.

5. Bondan EF, Lallo MA, Sinhorini IL, Baz EI, Paulino CA, Graça DL. Ultrastructural investigation on the brainstem remyelination after local ethidium bromide injection in rats immunosuppressed with dexamethasone. Acta Microscopica 1999;8:709-710.

6. Bondan EF, Lallo MA, Sinhorini IL, Pereira LAV, Graça DL. The effect of cyclophosphamide on brainstem remyelination following ethidium bromide injection in Wistar rats. J Submicrosc Cytol Pathol 2000;32:603-612.

7. Graça DL. Investigation into ethidium bromide induced-demyelination in the central nervous system. Thesis (PhD), University of Cambridge, Cambridge, 1986.

8. Graça DL, Blakemore WF. Delayed remyelination in rat spinal cord following ethidium bromide injection. Neuropathol Appl Neurobiol 1986;12:593-605.

9. Graça DL, Pereira LAV. Dinâmica da impregnação celular pelo brometo de etídio "in vitro" e "in vivo" (Abstr). Porto Alegre: Anais da 42a Reunião da Sociedade Brasileira para o Progresso da Ciência (SBPC), 1990:430-431.

10. Pereira LAV, Dertkigill MSJ, Graça DL, Cruz-Höfling MA. Dynamics of remyelination in the brain of adult rats after exposure to ethidium bromide. J Submicrosc Cytol Pathol 1998; 30:341-348. 
11. Yajima K, Suzuki K. Ultrastructural changes of oligodendroglia and myelin sheats induced by ethidium bromide. Neuropathol Appl Neurobiol 1979;5:49-62.

12. Yajima K, Suzuki K. Demyelination and remyelination in the rat central nervous system following ethidium bromide injection. Lab Invest 1979;41:385-392.

13. Bondan EF, Lallo MA. Mielinização, desmielinização e remielinização no SNC: aspectos histofisiológicos relevantes à formação e integridade da mielina central. Rev Inst Ciênc Saúde 1998;16:103-111.

14. Leibowitz S, Hughes RAC. Immunology of the nervous system. London: Edward Arnold, 1983:2-16.

15. Sternberger NH. Multiple sclerosis as a autoimunne disease: vascular antigens. Res Immunol 1989;140:181-187.

16. Janzer RC, Raff MC. Astrocytes induce blood-brain barrier properties in endothelial cells. Nature 1987;325:253-257.

17. Risau W. Induction of blood-brain barrier endothelial cell differentiation. Ann NY Acad Sci 1991;405:405-419.

18. Peters A, Palay SL, Webster HdeF. The fine structure of the nervous system. 3. Ed. New York: Oxford Univ Press, 1991:290-295.

19. StewartPA, Coomber BL. Astrocytes and the blood-brain barrier. In Fedoroff S, Verdanakis A (eds.). Astrocytes: development, morphology and regio- nal specializations of astrocytes. London: Academic Press, 1986:311-323.

20. Bundgaard M. Pathways across the vertebrate blood-brain barrier morphological viewpoints. Ann NY Acad Sci 1986;481:7-18.

21. Reese TS, Karnovsky MJ. Fine structural localization of a blood-brain barrier to exogenous peroxidase. J Cell Biol 1967;34:207-217.

22. Felts PA, Smith KJ, Tilt E. Blood-brain barrier function in central demyelinating lesions repaired by Schwann cell remyelination. Ann NY Acad Sci 1991;633:615-616.

23. Weller RO. Pathology of multiple sclerosis. In Matthews WB, Acheson ED, Batchelor Jr (eds.). Mc Alpine's multiple sclerosis. Edinburgh: Churchill Livingstone, 1985:301-343.

24. Hsu S-M, Raine L, Fanger H. A comparative study of the peroxidaseantiperoxidase method and an avidin-biotin complex method for studying polypeptide hormones with radioimmunoassay antibodies. Am J Clin Pathol 1981;75:734-738.

25. Majno G, Palade GE. Studies on inflammation: I. The effect of histamine and serotonin on vascular permeability. An electron microscope study. J. Biophys Biochem Cytol 1961;11:571-605.

26. Reynolds R, Wilkin GP. Cellular reaction to an acute demyelinating/ remyelinating lesion of the rat brainstem: localization of GD3 ganglioside immunoreactivity. J Neurosc Res 1993;36:405-422. 